\title{
Mensagens falsas sobre o novo coronavírus: legitimidade e manipulação na luta de classes
}

Mensajes falsos sobre el nuevo coronavirus: legitimidad y manipulación en la lucha de clases

False messages about the coronavirus: legitimacy and manipulation in the class struggle

\author{
Guilherme DA SILVA LIMA \\ Universidade Federal de Ouro Preto - Brasil \\ glima@ufop.edu.br \\ Marcos MORAES CALAZANS \\ Universidade Federal de Ouro Preto - Brasil \\ calazans@ufop.edu.br

\section{Luciana MASSI} \\ Universidade Estadual Paulista - Brasil \\ luciana.massi@unesp.br
}

Chasqui. Revista Latinoamericana de Comunicación

N.o 147, agosto-noviembre 2021 (Sección Diálogo de Saberes, pp. 259-280)

ISSN 1390-1079 / e-ISSN 1390-924X

Ecuador: CIESPAL

Recibido: 12-01-2021 / Aprobado: 10-07-2021 


\title{
Resumo
}

Este trabalho tem como objetivo analisar a composição das primeiras mensagens falsas sobre o novo coronavírus e Covid-19 que circularam no Brasil visando problematizar as relações entre forma e conteúdo que creditam legitimidade às mensagens e como elas estão inseridas na luta de classes. Usamos as contribuições de Volóchinov, acerca na natureza da linguagem associadas a aportes do campo do materialismo histórico e dialético, para analisar 11 mensagens, sendo duas analisadas com maior profundidade. Os resultados indicaram que as comunicações analisadas estão inseridas na luta de classe buscando manipular o interlocutor e que as mensagens falsas se apropriaram e mobilizaram elementos das esferas da Ciência e do Jornalismo, para dar o efeito de credibilidade e legitimidade.

Palavras-chave: mensagens falsas, coronavírus, luta de clases, ideología, manipulação

\begin{abstract}
This paper aims to analyze the first false messages composition on the new coronavirus and Covid-19 that circulated in Brazil. The analysis problematize the relationships between form and content that give legitimacy to the messages and how they are inserted in the class struggle. We used the contributions of the Circle, especially Volóchinov, on the nature of language associated with contributions from the field of historical and dialectical materialism, to analyze 11 messages, two of which were analyzed deeply. The results indicated that false communications are inserted in the class struggle seeking to manipulate the interlocutor and they appropriated and mobilized elements, mainly from the spheres of Science and Journalism, to give the effect of credibility and legitimacy.
\end{abstract}

Keywords: fake news, coronavirus, class struggle, ideology, manipulation

\section{Resumen}

Estetrabajotienecomo objetivoanalizarlacomposición delos primerosmensajes falsos sobre el nuevo coronavirus y Covid-19 que circularon en Brasil con el fin de problematizar las relaciones entre forma y contenido que dan legitimidad a los mensajes y cómo se insertan en la lucha de clases. Utilizamos los aportes de Volóchinov, sobre la naturaleza del lenguaje asociado a aportes del campo del materialismo histórico y dialéctico, para analizar once mensajes, dos de los cuales fueron estudiados con mayor profundidad. Los resultados indicaron que las comunicaciones se insertan en la lucha de clases buscando manipular al interlocutor y que los mensajes falsos se han apropiado y movilizado elementos de la ciencia y el periodismo, para dar el efecto de credibilidad y legitimidad.

Palabras clave: mensajes falsos, coronavirus, lucha de clases, ideología, manipulación 


\section{Introdução}

A pandemia do novo coronavírus reflete uma crise econômica, social e histórica, cuja explicação não se limita a biologia ou a natureza (Mascado, 2020). De acordo com a OMS, essa doençajá infectou mais de 84 milhões de pessoas, levando a óbito mais de 1,89 milhão até 08/01 (WHO, 2020). A gravidade da doença e a rapidez do contágio levou muitos países a declararem quarentena e restringir as atividades sociais. Contudo, nem todos têm condições de aderir ao distanciamento, fato que denunciou problemas intrínsecos do sistema de produção capitalista e a gravidade das desigualdades sociais. A doença atinge mais gravemente a classe trabalhadora, pobres, negros e marginalizados, uma vez que possuem acessos limitados aos recursos para prevenção e tratamento.

Para além da crise sanitária e econômica, a Covid-19 fomentou a ampliação de uma crise comunicativa (Dasilva, Ayerdi \& Galdospín, 2020) de circulação de mensagensfalsas, situação que motivou esta entidade a cunhar o termo Infodemia (Infodemic). As mensagens falsas possuem diversos formatos dentre eles as notícias falsas, popularmente conhecidas porfake news, que são caracterizadas pela reprodução de características composicionais de comunicações oficiais de veículos de comunicações (Tandoc Jr., Lim \& Ling, 2018), e os boatos falsos que podem ser compreendidos como comunicação falaciosa com ou sem elementos que supostamente validam o conteúdo comunicado. ${ }^{1}$

As primeiras mensagens falsas sobre o novo coronavírus continham diversos propósitos que se estendiam desde a minimização da gravidade da doença até a difusão de (falsas) descobertas de medicamentos e tratamentos capazes de curá-la (Lana et. al., 2020; Alves Silva, Medeiros \& Correo, 2020). Ao mesmo tempo em que as notícias falsas foram surgindo, diversas instituições atuaram na tentativa de conter sua disseminação. Ressaltamos, as iniciativas de verificação desempenhadas por veículos tais como: Latam Chequea, Agência Lupa, Estadão verifica, Aos fatos, etc.

Buscando compreender as mensagens falsas sobre a Covid-19 e o novo coronavírus, este trabalho tem como objetivo analisar a composição das primeiras mensagens falsas que circularam no Brasil, especialmente para problematizar as relações entre forma e conteúdo que creditam legitimidade às mensagens e como elas estão inseridas na luta de classes. Para isso, usamos as contribuições de Volóchinov associadas às contribuições de outros aportes do campo do materialismo histórico e dialético.

\section{Sobre a circulação de mensagens falsas na comunicação social}

Asmensagensfalsaspodem ser compostas porumadiversostipodecomunicação, "pode incluir conteúdo falso que imita os media jornalísticos de legado ou pode

1 Consideramos notícias e boatos diferentes; utilizaremos o termo mensagens falsas para contemplar as diversas possibilidade de comunicar informações ou fatos falsos. 
envolver métodos mais subtis, como false flag operations, fornecer citações ou histórias imprecisas a intermediários inocentes ou amplificar conscientemente informações tendenciosas ou enganosas" (Alcantara \& Ferreira, 2020, p. 140). Ao realizarem uma revisão buscando definir o termo fake news, Tandoc Jr. et al. (2018) ressaltam que as mensagens falsas estão encobertas sob um verniz de legitimidade, pois imitam a aparência de comunicações reais (layout, estilo de escrita, tipo de imagens, etc.). Elas também podem ser compreendidas em duas dimensões, a factualidade, isto é, os graus com que as notícias abordam um fato real, e a intencionalidade dos autores.

Eles indicaram que a proliferação de mensagens falsas pode estar associada ao fato de cidadãos sem formação e experiência atuarem como comunicadores ou porque o compartilhamento de ideias entre pessoas conhecidas fornece uma impressão de legitimidade (Tandoc et al. 2018). As transformações na comunicação, impulsionadas pela liberdade relativa na veiculação de conteúdos na internet e, em especial, nas mídias sociais, proporcionam ambientes "com abundância de informação e baixo índice de hierarquia no processo de produção, avaliação e disseminação" fato que propicia o "surgimento de informações com baixa credibilidade atualmente conhecidas como pós-verdade, desinformação ou fake news" (Delfino, Pinho Neto \& Sousa, 2019, p. 7). Associado a isso, a falta e/ou competência para verificar as informações potencializa o poder de disseminação das mensagens falsas.

Apesar da crescente presença das mensagens falsas na comunicação social, esse fenômeno não é originário do século XXI, essas práticas foram registradas em outros momentos da história humana (Cortada \& Aspray, 2019). Um dos casos mais famosos ocorreu em 10 de outubro de 1938, quando um trecho da obra a guerra dos mundos foi adaptado e transmitido por meio de diversos gêneros radiofônicos dentre eles, boletins jornalísticos falsos (Schwartz, 2015). Recentemente, percebeu-se a intensificação da influência das mensagens falsas nas decisões eleitorais (Estados Unidos e Reino Unido em 2016, Brasil em 2018), que já acontecia desde o século XIX (Cortada \& Aspray, 2019), e o consequente esforço da sociedade em combatê-las.

As mensagens sobre o novo coronavírus e Covid-19 também adentraram o campo da política. Dasilva et al. (2020) ressaltam que a maioria dos atores que postaram mensagens sobre o coronavírus no Twitter entre janeiro e março de 2020 estão relacionados à disputa política entre democratas e republicanos (EUA), sendo Donald Trump um dos protagonistas. Eles perceberam que "simpatizantes de ambos os lados se acusam mutuamente de mentir sobre o coronavírus [...] e, em suas mensagens, acusam jornalistas e meios de comunicação [...] de publicar notícias falsas" (Dasilva et al., 2020, p. 16, tradução livre). Ainda sobre o contexto americano, posturas conservadoras tenderam a minimizar a crise sanitária, além de associá-la a conspirações e reconhecer menos as notícias falsas (Calvillo, Ross, Garcia, Smelter \& Rutchick, 2020). 
A relação entre as notícias falsas e a política assumiram algumas formas. Mascaro (2020, p. 15) afirma que, assim como Trump, a aposta de Bolsonaro é "investir na crise como reação à crise", começando com o negacionismo depois adotando a estratégia política de negar a realidade que governa. Por outro lado, Hua e Shaw (2020) destacam que na China o Estado rapidamente tomou providências para conter a propagação de mensagens falsas sobre o novo coronavírus, de modo que houve ações articuladas entre o Estado, empresas e ação popular.

Allcott e Gentzkow (2017) ressaltam que as motivações para a produção das mensagens falsas podem ser tanto financeiras quanto ideológicas. Particularmente, entendemos que ambas estão relacionadas uma vez que infraestrutura (economia) e superestrutura (ideologia) interagem mutuamente em uma relação dialética. Nesse sentido, a análise das relações ideológicas estabelecidas ao redor das mensagens falsas contempla um espectro mais amplo que as disputas político-partidárias.

Parte da literatura científica contemporânea (Fernandez, 2017; Tandoc et al., 2018; Turk, 2018; Delfino et al., 2019) associa o fenômeno das mensagens falsas à tecnologia devido à inevitável identificação com os novos mecanismos de comunicação proporcionados pelas mídias sociais. Turk, por exemplo, evidencia que nesse contexto "as mídias sociais têm má reputação porque têm sido um importante impulsionador para o consumo de notícias falsas" (2018, p. 13, tradução livre) e acrescenta que as pessoas passaram a consumir informações falsas por meio das mídias sociais e pelos buscadores online. Para além das mídias sociais, Fernandez (2017) salienta que o acesso à tecnologia de publicação na internet por meio de domínios próprios também contribuiu para a disseminação das mensagens falsas, pois elementos da forma (nome do site, layout, etc.) são projetados para parecer com diversos sites de notícia reconhecidos como legítimos.

O vínculo entre a tecnologia e o consumo de mensagens falsas não é acrítico, uma vez que muitos desses trabalhos reconhecem as limitações das análises desenvolvidas. Ressaltamos que, embora seja evidente as transformações na vida cotidiana mediada pela tecnologia, é questionável o estabelecimento de vínculos imediatos e exclusivos entre a forma de uso das ferramentas tecnológicas e as tomadas de decisões pelos indivíduos (como é o caso da decisão de acreditar ou não em mensagem recebida por redes sociais ou mesmo de replicá-las).

Levada ao limite, a tentativa de compreender a tecnologia como origem das mensagens falsas produz uma falsa autonomização do papel da tecnologia que conduz a explicações parciais e/ou equivocadas dos problemas sociais, uma vez que atribui um poder exagerado, e às vezes absoluto, da tecnologia sobre as escolhas individuais e as relações sociais. $O$ destaque exclusivo da relação entre a tecnologia e sua influência nos sujeitos foca apenas no poder fantasmagórico decorrente do fetiche da mercadoria (Marx, 2013). No fetichismo tecnológico, a tecnologia é uma instância não-social, travestida de pura racionalidade 
técnica, cujas explicações estão baseadas na eliminação das determinações econômicas e sociais que as engendram (Feenberb, 1999). Este é o caso da posição que atribui exclusivamente às mídias sociais o motivo das eleições de políticos que são considerados no espectro da extrema direita. O materialismo histórico e dialético alega que este, como qualquer outro fenômeno social, tem raízes históricas e econômicas, por isso estas devem ser consideradas nas investigações científicas, ainda que em diferentes níveis de profundidade.

Em acréscimo, mensagem falsa não é uma categoria genérica e abstrata distante dos conflitos de classe da sociedade, apartada das disputas acirradas e normalmente determinantes pelo controle hegemônico ${ }^{2}$ no mercado da comunicação; especialmente porque essas são as condições concretas de produção discursiva. É necessário considerar que cada mensagem falsa expressa um enunciado concreto, inscrito historicamente e determinado pelas diversas contradições sociais.

Destacamos que as tecnologias promovem mediações entre os seres humanos, a natureza e a sociedade. Neste sentido, a relação entre mensagens falsas e tecnologia não pode ser estudada como relação processo-produto e, menos ainda, como um complexo isolado das relações do indivíduo com a sociedade. Ressaltamos que é necessário que a investigação científica também se atente para as condições infraestruturais que determinam o fenômeno das mensagens falsas. Por isso, apresentamos um estudo que articula os elementos internos das mensagens com os aspectos infraestruturais da sociedade capitalista, numa tentativa de compreender tanto as características particulares quanto as determinações econômicas e sociais que atuam sobre as mensagens falsas. Entendemos as mensagens falsas como um fenômeno complexo que é produto histórico e social das relações entre base econômica, a superestrutrura (especialmente a ideologia) e o conflito entre as classes sociais que as produzem.

\section{Constituição do corpus de análise}

Para investigar as primeiras mensagens falsas que circularam no Brasil adotamos a análise documental. A seleção dos dados tomou como referência o sítio Latam Chequea, que é uma iniciativa que congrega agências verificadoras de 17 países ibero-americanos, dentre elas quatro agências verificadoras brasileiras, a saber: Agência Lupa, Aos Fatos, Estadão verifica e AFP (filial brasileira). Além disso, Latam Chequea utiliza a base internacional de verificadores estabelecida pela International Fact-Checking Network (IFCN), outro fato que legitima a relevância da base de dados.

Os dados foram compostos por todas as mensagens falsas que circularam no Brasil nos meses de janeiro e fevereiro de 2020 e foram registradas em Latam Chequea, no total de onze. O baixo número de comunicações falsas nos meses

2 "A hegemonia pressupõe a conquista do consenso e da liderança cultural e político-ideológica de uma classe ou bloco de classes sobre as outras" (Moraes, 2010, p. 54). 
indicados é compreensível, especialmente porque a primeira divulgação oficial de caso de Covid-19 registrado no Brasil ocorreu 26/02/2020. Devido à dimensão deste trabalho, analisamos descritivamente todas as mensagens falsas (Apêndice 1). Em seguida, selecionamos duas mensagens que foram analisadas detalhadamente para exemplificar relações complexas entre forma e conteúdo na composição de comunicações falaciosas buscando analisar os elementos que creditam legitimidade.

A análise está baseada, principalmente, nas contribuições de Volóchinov (2017; 2019), que defende uma interpretação da linguagem e da comunicação baseada no materialismo histórico e dialético. Por isso, entende que a comunicação é um processo instaurado entre sujeitos socialmente organizados em determinado contexto histórico e, como tal, é impossível analisá-lo excluindo seus contextos de produção concreta (econômicos e sociais). Para Volóchinov (2017) a comunicação é realizada por signos ideológicos capazes de refletir e refratar a realidade na comunicação social, ao passo que eles estão presentes em todas as atividades humanas.

Baseado nessas e em outras considerações, Volóchinov (2017, p. 110) ressalta três exigências metodológicas: "1. Não se pode isolar a ideologia da realidade material do signo; 2. Não se pode isolar o signo das formas concretas da comunicação social; 3. Não se pode isolar a comunicação e suas formas da base material". Com base nessas orientações, a análise considerou tanto as condições concretas de produção quanto as características discursivas das mensagens falsas, que foram separadas em duas seções.

\section{Condições de produção das mensagens falsas e suas relações ideológicas e de classe}

A produção e circulação de notícias falsas são determinadas pelas condições infraestruturais da sociedade. Volóchinov (2017, p. 110-111) destaca:

Para que um objeto, independentemente do tipo da sua realidade, entre no horizonte social de um grupo e provoque uma reação ideológica sígnica, é necessário que ele esteja relacionado com as premissas socioeconômicas essenciais da existência desse grupo; é necessário que, de algum modo, ele toque, mesmo que parcialmente, as bases da existência material desse grupo.

A partir dessa consideração podemos compreender melhor os motivos para a ampla circulação das mensagens falsas sobre o novo coronavírus e Covid-19 na sociedade contemporânea. A pandemia evidencia e agrava uma crise do modelo de relação social do capitalismo — cujo modo de produção é a crise (Mascaro, 2020) - uma vez que a situação exigiu da sociedade o distanciamento social e a paralisação de diversos setores da produção econômica. Esse cenário impôs obstáculos para a manutenção do salário de inúmeros trabalhadores e a consequente produção de mais valia (lucro) para os detentores dos meios de 
produção. A negação da pandemia e da gravidade da doença é a forma mais direta de tentar manter a crise como reação à crise (Mascaro, 2020), nesse caso por meio de interpretações que visam a manipulação.

No conflito de classes, entre capital e trabalho, a manipulação é uma regra fundamental, ainda que sua forma varie em cada período histórico. Ao discutir a relação entre práxis ${ }^{3}$ cotidiana e ontologia, Lukács (2012) demonstra que a manipulação é um princípio que regeu o modo como classes dominantes acomodaram sua concepção de mundo e teorias ontológicas às necessidades práticas mais imediatas que emergem na vida cotidiana. Lukács acrescenta que dos estágios mais desenvolvidos do capitalismo:

Resulta a necessidade econômica da manipulação cada vez mais sofisticada do mercado, desconhecida tanto na época do livre-comércio quanto no início do capitalismo monopolista. Paralelamente a isso — no fascismo e na luta contra ele- emergem novos métodos de manipulação da vida política e social que intervêm profundamente até na vida individual e —numa fértil interação com a já mencionada manipulação econômica - apoderam-se de setores cada vez mais amplos da vida. (2012, p. 46)

A manipulação é uma tendência que corrobora para a realização dos interesses econômicos e políticos das classes dominantes.

Atualmente as formas de manipulação são produzidas de diversas formas, dentre elas o espetáculo, que, segundo Kulak, é um "mecanismo que consiste em relações recíprocas entre comunicação de massa, cultura industrial, propaganda política e cotidianidade" que conjuntamente fornecem a base para "manipular o indivíduo sobre o que fazer, pensar e consumir" (2020, p. 12, tradução livre). Entendemos que a produção e disseminação de mensagens falsas seja uma das formas de produzir espetáculos ou hiperespetácutos (fenômeno que "oferece, individualmente, satisfação emocional máxima, mesmo que não possa fornecer o mínimo de satisfação material" (Kulak, 2020, p. 13, tradução livre)).

Assim, a manipulação é produzida por meio de um conjunto de práticas, em que os meios de comunicação são componentes essenciais, uma vez que podem inculcar nos indivíduos os valores, crenças e códigos de conduta que criam as condições para a integração dos indivíduos nas estruturas institucionais da sociedade (Chomsky \& Herman, 2002).

Considerando que as formas de comunicação discursiva "são inteiramente determinadas pelas relações de trabalho e pelo regime sociopolítico" (Volóchinov, 2017, p. 109), as mensagens falsas são fruto de um modelo de produção que busca sua manutenção mesmo que isso custe a dizimação a classe trabalhadora. Nesse contexto, a manipulação se apresenta como prática que visa deturpar a interpretação sobre o real.

3 Entendemos que a práxis expressa a unidade dialética entre teoria e prática na atividade humana (Silveira Jr., 2014). 
Vale ressaltar que essa mesma situação (pandemia), que impõem obstáculos para a produção de mais valia, propicia oportunidades para acentuar a exploração da classe trabalhadora, uma vez que contribui para a produção ideológica acerca da aceitação da precarização para a manutenção dos postos de trabalho. A ideologia não é apenas fruto da infraestrutura econômica ela também retroalimenta a base da produção humana e a si própria (Williams, 2011). Assim, o fenômeno das mensagens falsas é uma das expressões ideológicas do conflito de classes, além de ser parte da práxis de grupos que atuam a serviço de diferentes frações das classes dominantes. Van Duyn e Collier corroboram com essa análise à medida que destacam efeitos dos discursos da elite sobre mensagens falsas na avaliação pública:

Nossos resultados indicam que o discurso da elite sobre notícias falsas pode influenciar a capacidade do público de identificar com precisão o que é notícia falsa e o que não é. Indivíduos induzidos pelo discurso da elite sobre notícias falsas identificaram notícias reais com menos precisão do que aqueles que não foram induzidos. (2019, p. 41, tradução livre)

Em meio a produção de ferramentas que promovam a manipulação há a instauração de uma contradição acerca do monopólio da comunicação, que está expressa na disputa de grandes empresas multinacionais. No caso brasileiro temos o exemplo das organizações globo, considerada o maior conglomerado de empresas de comunicação do país e um dos maiores do mundo, que controla canais televisivos e de rádio, jornais, revistas, portais na web, além de diversas filiais espalhadas pelo país. De outro lado estão as empresas de mídias sociais (Facebook, Twitter, Youtube, Whatsapp, etc) que instauraram novos modelos comunicativos.

Conforme descrito pelo modelo de propaganda de Herman e Chomsky (2008), os grupos políticos dominantes detêm o controle dos principais meios de comunicação com os quais produzem e reproduzem o discurso oficial possuindo em suas mãos todas as condições para a produção de narrativas consagradas como "mensagens verdadeiras". Contudo, com a emergência das mídias sociais há uma nova condição de produção comunicativa que instaura a disputa pela hegemonia da comunicação social.

Após as recentes interferências das mensagens falsas nas disputas eleitorais, a Organização das Nações Unidas e diversas outras agências ligadas ao núcleo do establishment iniciaram uma campanha internacional contra as mensagens falsas. $\mathrm{O}$ ataque das mensagens falsas a outros setores como a saúde pública, motivado pelas informações acerca do novo coronavírus, antivacina, etc., fortaleceu a importância do seu combate. Para esse núcleo, as mensagens falsas, dentre outras coisas, comprometem a credibilidade dos processos eleitorais e, por conseguinte, do próprio sistema. De outro lado, os monopólios de comunicação apoiam, de forma resoluta, as campanhas contra mensagens 
falsas aproveitando para impor limites às grandes empresas de mídias sociais na disputa econômica de mercado das comunicações.

Vale salientar que a contradição estabelecida entre mentira e verdade sobre o novo coronavírus e Covid-19 é o motor para a produção das mensagens falsas e é reconfigurada na luta de classe à medida que consideramos que a mentira é uma ferramenta para a opressão e a verdade para a emancipação humana. Contudo, as disputas entre a extrema direita e a direita, centro ou esquerda (que concorre às eleições) sobre as narrativas acerca da pandemia não expressam contradições internas ao modo de produção, uma vez que todas as vertentes desse embate não o questionam, mas, ao contrário, o legitimam e trabalham para sua manutenção. Nesse sentido, essas contradições são estabelecidas no domínio ideológico, atinentes às classes dominantes, em uma disputa pela hegemonia, no sentido de estabelecer um "bloco ideológico que permite à classe dirigente manter o monopólio intelectual", que por sua vez determina a ideologia e "garante não apenas que a classe fundamental exerça sua função dirigente, mas também sua função dominante" (Alves, 2010, p. 79).

\section{A incorporação de elementos de legitimidade nas comunicações falsas sobre o novo coronavírus}

Outra consideração que devemos fazer acerca das mensagens falsas é sobre a crença que as pessoas têm nelas. Ressaltamos a necessidade de afastar uma interpretação imediatista que desconsidera as ações do(s/as) produtor(es/ as) do enunciado e transfere para o sujeito que interpreta a responsabilidade de compreender corretamente e identificar as falsidades. Na cotidianidade, alguns podem entender que crer em uma mensagem falsa está relacionado com a formação e a capacidade crítica da pessoa para interpretar informações que circulam nas mídias sociais. Por outro lado, não podemos nos apoiar na "falsa tendência a reduzir tudo a uma única consciência, a dissolver nela a consciência do outro (do intérprete)" (Bakhtin, 2017, p. 35). Vale ressaltar que a compreensão é um processo estabelecido entre sujeitos (Autor 1), se excluirmos os locutores ou interlocutores/destinatários não seremos capazes de analisar adequadamente $o$ complexo fenômeno das mensagens falsas.

Para analisar esse fenômeno, apresentamos a Tabela 1 (Apêndice) com uma breve síntese das onze mensagens falsas que compõem a base de dados. Tandoc Jr., Lim e Ling (2018) ressaltam que as notícias falsas são produzidas em meio a elementos de legitimidade. Entendemos que esses elementos são essenciais para a instauração da manipulação. Assim, os produtores das mensagens falsas incorporam e replicam elementos que produzem o efeito de credibilidade à comunicação. As mensagens da Tabela 1 indicam, principalmente, três características das mensagens falsas que contribuem para a manipulação, a saber: apropriação de elementos científicos e tecnológicos (mensagens 1, 4, 5, $6,7,10$ e 11), mobilização do imaginário popular (mensagens $1,3,4,5,6,9$ e 11) 
e distorção de informações (mensagens $2,3,6,9,10$ e 11). Tais características produzem o efeito de legitimidade à mensagem, seja pela proximidade dos temas com os interlocutores, seja pela credibilidade social das esferas de criação ideológica científica ejornalística. A partir desse conjunto selecionamos duas mensagens falsas cujos elementos discursivos exemplificam relações entre forma e conteúdo para a creditação do efeito de legitimidade.

Consideramos fundamental que a análise contemple os elementos estéticos da comunicação, uma vez que o "tema e a forma do signo ideológico estão ligados entre si de modo indissolúvel” (Volóchinov, 2017, 112, grifo do autor). Vale ressaltar que para o círculo:

O estético, sem perder suas especificidades formais, está enraizado na história e na cultura, tira daí seus sentidos e valores e absorve em si a história e a cultura, transpondo-as para um outro plano axiológico precisamente por meio da função estético-formal do autor-criador. (Faraco, 2011, p. 22)

Ao analisar o problema do conteúdo, do material e da forma na poética e na estética geral, Bakhtin (2010) tece considerações relevantes para compreender as relações desses elementos. Reconhecemos as diferenças entre a arte e a comunicação, contudo admitimos similaridades especialmente quando relacionadas à interdependência entre o conteúdo, o material e a forma.

A mensagem falsa "Paciente infectado com coronavírus se descontrola e morde jugular de médico nos EUA" incorpora diversos elementos que dão o efeito de legitimidade. $O$ primeiro deles é a reprodução da forma (Figura $1 \mathrm{e}$ 2), que se apropria de elementos de uma agência de comunicação brasileira. Volóchinov (2017, p. 177) ressalta que:

Para o falante, não importa o aspecto da forma, que permanece o mesmo em todos os casos do seu uso por mais variados que eles sejam. O que importa para ofalante é aquele aspecto da forma linguística graças ao qual ela pode aparecer em um contexto concreto, graças ao qual ela se torna um sinal adequado nas condições de uma situação concreta.

Nessa mensagem, a reprodução da forma (verbo-visual) do tweet do jornal cumpre seu propósito para contribuir com a produção ético-cognitiva do conteúdo. Para comparar, apresentamos uma imagem real extraída da conta de Tweeter do Jornal O Globo, na imagem recortamos partes da mensagem apresentada nesta mídia social (exclusivamente aqueles elementos disponíveis para a navegação) para apresentar os mesmos parâmetros da notícia falsa. 
Figura 1. Mensagem falsa (3-Tabela 1) sobre paciente infectado

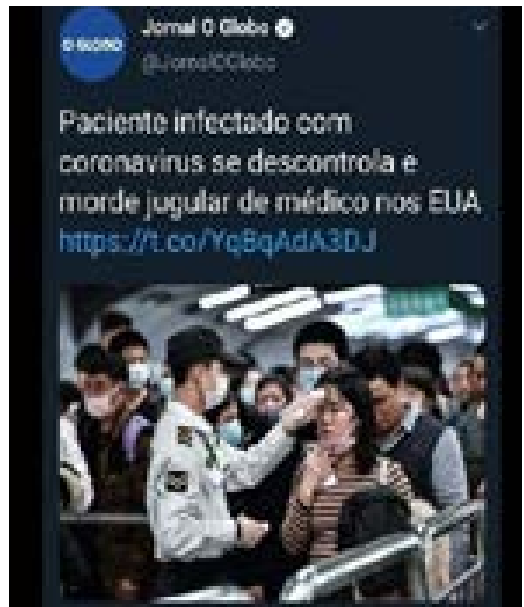

Fonte: Agência Lupa, publicado em 28/01/2020 (Marés, 2020)
Figura 2. Notícia real publicada no Twetter de Jornal O Globo

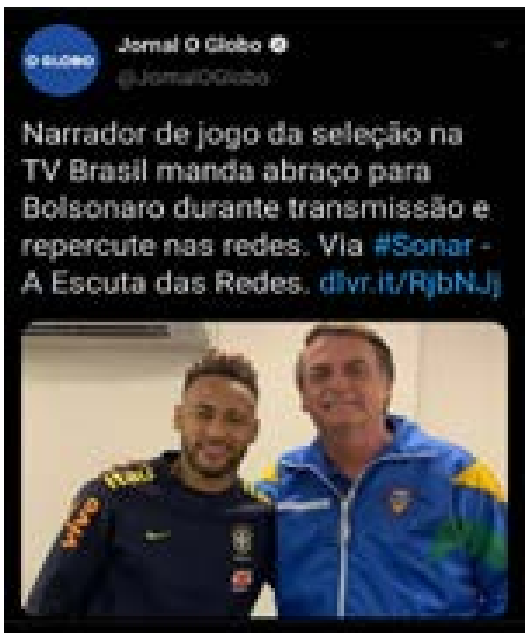

Fonte: Tweeter de Jornal O Globo em 14/10/2020

A comparação das Figuras 1 e 2 nos mostram a semelhança estrutural entre a notícia falsa e a notícia verdadeira. Evidentemente os conteúdos são diferentes, mas é notável a reprodução de elementos como a logomarca e a tag do jornal, a forma de organização do texto, da imagem e do hiperlink. Nesse caso, no ato de produção da notícia falsa há a consideração e incorporação de elementos que buscam o efeito de legitimidade e estão no horizonte social. Bakhtin (2010, p. 30) ressalta que:

O ato cognitivo encontra uma realidade já elaborada nos conceitos do pensamento pré-científico, mas, o que é primordial, o pensamento já vem apreciado e regulamentado pelo procedimento ético, prático e cotidiano, social e político; encontra-a religiosamente afirmada; e, finalmente o ato cognitivo provém da representação esteticamente ordenada do objeto, da visão do objeto.

O uso de um veículo do monopólio de imprensa ${ }^{4}$ de grande circulação como O Globo não é uma escolha fortuita dos produtores da notícia falsa. Visando produzir o efeito de legitimidade, que pode se consolidar como manipulação, o criador se apropria do material e da forma correspondente à de uma notícia de um veículo de comunicação. Assim, o autor da mensagem falsa usurpa de atributos e dos signos ideológicos (Logomarca, Tag, nome) para produzir o efeito de legitimidade e credibilidade, que são conferidos a esse veículo

4 Azevedo (2006) esclarece que no Brasil a imprensa é controlada por monopólios familiares e que "a Rede Globo praticamente detém o monopólio da audiência nacional" (p. 105). Em acréscimo destacamos que o controle da mídia está sob as mãos das classes dominantes, salvo exceções de práticas comunicativas comunitárias. 
de comunicação, transferindo-os para a notícia falsa. O autor se baseia, portanto, em uma antecipação acerca dos valores sociais compartilhados entre os interlocutores/destinatários a respeito do jornal. Com isso, no ato da produção há uma clara orientação que pretende conduzir a compreensão dos interlocutores, isto é, fazer com que eles entendam uma mentira como verdade. Uma das estratégias para legitimar a suposta fonte da mensagem falsa mobiliza a forma e conteúdo das redes sociais ao circular no Facebook uma mensagem com o formato de um tweet, supostamente indicando que essa foi uma postagem original do jornal nesta rede.

Além de assumir o layout de um tweet jornalístico, a mensagem falsa (Figura 1) apresenta um hiperlink que supostamente detalha a informação e isso as distingue de outras (Tabela 1) que se limitam a mensagem apresentada. $O$ hiperlink encaminha o interlocutor para uma página oficial do jornal O Globo, porém nela não consta a suposta mensagem indicada na postagem. Fato que mostra uma interrupção da cadeia enunciava, pois os elementos e elos que corroboram com o efeito de legitimação da mensagem se limitam internamente à comunicação falsa. Assim o encadeamento enunciativo posterior terá apenas as possibilidades de apreensão acrítica ou a apreciação negativa da mensagem (ainda que de diferentes formas), sob a alegação de que seu conteúdo é falso. Enquanto o conteúdo que contribui para legitimação da falsidade permanece interno, elementos da forma externalizam e se apropriam do externo, uma vez que indicam que a mensagem teria sido produzida pelo jornal O Globo.

Percebemos, assim, que as mensagens falsas são produzidas tendo como referência as mensagens da grande mídia, fato que já foi indicado por Fernandez (2017). Entendemos que este tipo de mensagens falsas buscam o efeito de legitimação a partir do pressuposto que na grande mídia só seriam veiculadas notícias reais. Por outro lado, verifica-se as transformações sociais e das condições de produção discursiva causadas pelas mídias sociais, uma vez que a imprensa tradicional também se apropriou das práticas comunicativas proporcionadas pelas mídias sociais. Nesse sentido, a disputa pela hegemonia entre os veículos de comunicação se apresenta de uma forma particular, uma vez que ao mesmo tempo em que a imprensa tradicional tenta limitar o poder das mídias sociais na comunicação jornalística ela também usufrui e retroalimenta as mídias sociais.

Para além da forma, vale ressaltar o conteúdo da mensagem "Paciente infectado com coronavírus se descontrola e morde jugular de médico nos EUA". Nela, o fragmento "se descontrola e morde a jugular" tem destaque devido ao efeito de sensação proporcionado pelo espetáculo do extraordinário e corrobora com as representações do imaginário apocalíptico (frequentemente representado no cinema por meio de zumbis e vampiros em contextos póspandêmicos), indicando mais uma vez um processo de antecipação acerca das interpretações dos interlocutores. A rigor esse efeito do conteúdo não confere, 
por si mesmo, a credibilidade, mas pode contribuir para o interlocutor produzir o sentido de aceitação da situação devido sua previsão pela ficção.

A análise desse caso mostra a incorporação de valores e sentidos histórica e culturalmente situados nos aspectos estéticos do discurso (Faraco, 2011). A comunicação, por sua vez, agrega em seu conteúdo e forma as contradições históricas da sociedade, dentre elas a disputa pela hegemonia da comunicação que tem ocorrido por meio do embate entre os veículos tradicionais de comunicação e as mídias sociais.

Outra estratégia que também encontramos nas primeiras mensagens falsas é a incorporação de supostas evidências científicas. Tal como ocorre com a próxima mensagem que analisamos (Figura 3). Ela circulou no Facebook e no seu final há um link que encaminha para um artigo científico ${ }^{5}$ disponível no modelo preprint.

A Figura 3 apresenta um boato produzido a partir do uso de um artigo científico, para induzir a interpretação de que o novo coronavírus foi produzido artificialmente. Nessa mensagem a reprodução da forma aparece de modo diferente da mensagem anterior, uma vez que não há reprodução da estrutura de uma notícia ou de outro gênero discursivo usado pelos grandes veículos de imprensa.

Figura 3. Comunicação no Facebook que incorpora elementos da cultura científica

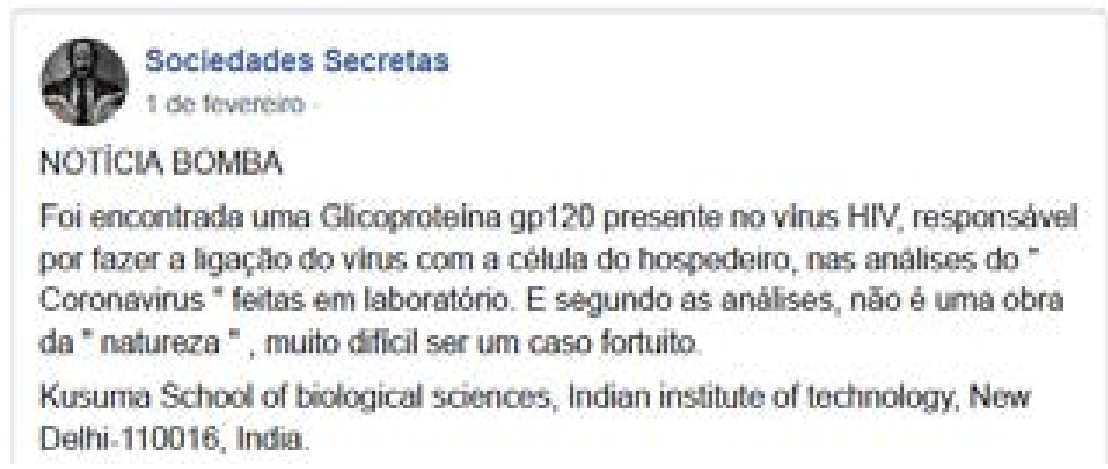

Fonte: Facebook, Sociedades Secretas, publicado em 01/02/2020

A mensagem apresenta a replicação de termos oriundos da esfera científica, a saber: glicoproteina gp120; hiv; vírus; célula; hospedeiro; análises; laboratório. De acordo com Bakhtin (2017, p. 42) "Não pode haver 'sentido em si', ele só existe para outro sentido" e acrescenta "Por isso não pode haver o primeiro

5 Pradhan, P. et al. (2020), "Uncanny similarity of unique inserts in the 2019-nCoV spike protein to HIV-1 gpl20 and Gag". BIORIV (preprint), 202. https://www.biorxiv.org/content/10.1101/2020.01.30.927871v1.full. pdf?fbclid=IwAR2qB6OLzASLgQEBUt7DwXj5tWNfgoLhiu2iSSO5EIAnneDMYhNHu7JAwJc 
nem o último sentido, ele está sempre situado entre os sentidos, é um elo na cadeia dos sentidos, a única que pode ser real em sua totalidade". Assim, a enunciação desses termos produz sentidos associados à Ciência além do efeito de que o enunciado foi produzido nessa esfera de criação ideológica, condição que também apresenta uma orientação ético-cognitiva particular que busca se apropriar dos valores atribuídos à ciência e a tecnologia.

Destacamos o uso do termo Glicoproteina gp120, um termo técnico restrito a um grupo de profissionais do campo científico, como signo ideológico, pois é um elemento-chave usado para estabelecer os vínculos entre a mensagem e a cultura científica. No contexto, seu significado tem pouca importância, uma vez que a grande maioria dos interlocutores podem não ter domínio conceitual do tema. Portanto, a ação do autor mobiliza uma antecipação negativa, que está baseada no desconhecimento associado à possível produção ético-cognitiva do interlocutor por meio da aceitação da interpretação devido à impossibilidade deste contrapor signos antagônicos. Há a criação de um vínculo que está fundamentado na relação entre a inacessibilidade do conhecimento científico e o valor social atribuído a ciência.

Ademais, o artigo científico é usado para produzir o efeito de legitimidade e credibilidade à produção acerca da origem do novo coronavírus. Com isso, podemos entender que a manipulação tenta ser estabelecida por meio de uma forma de hiperespetáculo (Kulak, 2020), uma vez que a mensagem pode gerar o sentido de satisfação emocional para aqueles acreditavam no argumento da produção do vírus em laboratório, devido a validação científica alegada pela mensagem. Para induzir esse efeito, há um elo enunciativo corroborativo que se estende para além da mensagem (o artigo), contudo este elo não se prolonga progressivamente para a consolidação e legitimação do conteúdo. A respeito do mérito do artigo, Ioannidis ressalta que "o artigo foi rapidamente criticado como altamente defeituoso e os autores o retiraram em poucos dias” (2020, p. 1, tradução livre).

\section{Discussões e considerações finais}

Este trabalho teve como objetivo analisar as primeiras mensagens falsas sobre o novo coronavírus que circularam no Brasil, para isso teve como fundamento as contribuições teórico-metodológicas, especialmente, de Volóchinov (2017; 2019), associadas a outros aportes do materialismo histórico e dialético. As análises não esgotaram os problemas, características e contradições inerentes às mensagens falsas, por exemplo identificamos contradições acerca da relação entre ciência e pseudociência nas mensagens, que por uma questão de escopo e dimensão do trabalho não foi aprofundada. Os resultados dessa pesquisa indicaram caminhos para a investigação no campo dos estudos do discurso e ensejam aprofundamentos para compreendermos melhor o fenômeno das mensagens falsas e desenvolvermos mecanismos para combatê-las, seja com o 
fortalecimento das práticas de verificação de mensagens, especialmente aquelas produzidas e destinadas para a classe trabalhadora, seja por meio da divulgação científica assumindo critérios de verdade pautados na prática social tal como indica Messeder Neto (2019).

Em síntese, os resultados indicaram que as comunicações analisadas se apropriaram e mobilizaram diversos elementos para dar o efeito de credibilidade e legitimidade às mensagens falsas. $\mathrm{O}$ ato de produção da comunicação falsa ocorre em um mundo pré-existente em meio a contradições determinadas pela luta de classes em que significações e valores criados socialmente circulam nos processos comunicativos.

As duas mensagens analisadas exemplificam como comunicações falsas mobilizaram aspectos de atividades que possuem prestígio social para a produção do efeito de legitimidade e tentam manipular os interlocutores para acreditar e, consequentemente, adotar condutas negacionistas sobre o novo coronavírus e a Covid-19. As análises indicaram também que as relações entre legitimidade, forma e conteúdo estão ancoradas em apreciações oriundas de esferas de criação ideológica (nos casos, Jornalismo e Ciência) que passam a compor artificialmente a mensagem por meio da reprodução de traços estéticos, éticos e cognitivos.

Para além da legitimidade, o discurso das mensagens falsas possui outra característica comum, que pode ser compreendida por meio do dialogismo, qual seja: a existência de uma fronteira absoluta entre os elos discursivos colaborativos. No caso das mensagens falsas, por ser falsa desde a origem, por mais que sejam estabelecidos vínculos artificiais que produzam o efeito de legitimidade, isto é, vínculos que corroborem para a produção e manutenção dos sentidos almejados, há um limite rígido que é estabelecido no momento em que um dos fatos é colocado em face da verdade. Isso de forma alguma é um impeditivo para a reprodução do discurso falacioso, entretanto, é uma fronteira para a produção de sentidos que contribuam para a produção do efeito de legitimidade e da manipulação. Assim o discurso das mensagens falsas possui uma relação dialógica particularmente definida por meio da aceitação acrítica ou pela contraposição dos enunciados subsequentes.

As contradições internas que apresentamos nas análises a respeito das condições de produção não são evidentes quando analisamos exclusivamente os elementos superficiais do discurso, especialmente, porque a "classe dominante tende a atribuir ao signo ideológico um caráter eterno e superior à luta de classes, apagar ou ocultar o embate das avaliações sociais no seu interior, tornando-o monoacentual" (Volóchinov, 2017, p. 113). Elas são contradições sociais estabelecidas na base da produção humana, que são refletidas e refratadas na comunicação. Os discursos indicam as pequenas acumulações quantitativas de mudanças sociais que ainda não se consolidaram como forma ideológica acabada (Volóchinov, 2017), como a disputa pela hegemonia da comunicação e 
a batalha pela narrativa sobre o novo coronavírus que atualmente está sendo vencida pelo núcleo do establishment.

É importante ressaltar que as mensagens falsas possuem características contrárias àquelas do conhecimento, em especial o científico, pois este é estruturado com base em uma pluralidade de apreciações que interagem, contrária e corroborativamente, em prol da consolidação de uma interpretação coerente do real.

A mensagem falsa, por sua vez, tem a característica de ser isolada, pois sua origem é fruto de uma desvinculação entre o ato cognitivo e a realidade. Por esse motivo, as mensagens falsas possuem limites rígidos quanto à produção de elos enunciativos corroborativos. Quando existem, os vínculos nas comunicações falaciosas são relações com outras mentiras, deturpações ou uso inapropriado de determinado saber, sem contar as situações em que há a produção de uma rede de informações e/ou práticas sociais que buscam sustentar a fraude. Contudo, esses possíveis prolongamentos enunciativos corroborativos se cessam quando se deparam com o fato verdadeiro.

As mensagens falsas são produzidas em meio a unidade dos contrários verdadeiro e falso, cuja contradição é o motor para essa prática comunicativa. $O$ autor sabe que a mensagem é falsa, por isso, reveste e circunscreve o conteúdo da mensagem em materiais e formas consolidadas que contribui para a produção do efeito de legitimidade que é desejado.

\section{Referências bibliográficas}

Alcantara, J., \& Ferreira R. R. A infodemia da "gripezinha": uma análise sobre desinformação e coronavírus no Brasil. Chasqui. Revista Latinoamericana de Comunicación, 145, 137161. doi: 10.16921/chasqui.v1i145.4315

Allcott, H., \& Gentzkow, M. (2017). Social Media and Fake News in The 2016 Election. Journal of Economic Perspectives, 31(2): 211-236. doi: 10.1257/jep.31.2.211

Alves, A. R. (2010). O conceito de hegemonia: de Gramsci a Laclau e Mouffe. Lua Nova: Revista de Cultura e Política, 80, 71-96. doi: 10.1590/So102-64452010000200004.

Alves Silva, M, Medeiros. F. B., \& Correo, K. A. C. (2020). Covid-19 e fake news: análise das notícias verificadas no site "Fato ou fake". Chasqui. Revista Latinoamericana de Comunicación, 145, 119-136. doi: 10.16921/chasqui.v1i145.4312

Azevedo, F. A. (2006). Mídia e democracia no Brasil: relações entre o sistema de mídia e o sistema político. Opinião Pública, 12(1), 88-113. doi:10.1590/So104-62762006000100004

Bakhtin, M. (2010). Questões de literatura e de estética. São Paulo: Hucitec editora.

Bakhtin, M. (2017). Notas sobre literatura, cultura e ciências humanas. São Paulo: Editora 34.

Cortada, J. W., \& Aspray, W. (2019). Fake News NationThe Long History of Lies and Misinterpretations in America. Lanham: Rowman \& Littlefield.

Calvillo, D. P., Ross, B. J., Garcia, R. J. B., Smelter, T. J., \& Rutchick, A. M. (2020) Political Ideology Predicts Perceptions of the Threat of COVID-19 (and Susceptibility to Fake News About It). Social Psychological and Personality Science, 11(8), 1119-1128. doi: 10.1177/1948550620940539

Dasilva, J. Á., Ayerdi, K., \& Galdospín, T. (2020). “Fake news y coronavirus: detección de los 
principales actores y tendencias a través del análisis de las conversaciones en Twitter". Profesional de la información, 29(3), e290308. doi: 10.3145/epi.2020.may.08

Delfino. S. S.; Pinho Neto, J. A., \& Sousa, M. R. (2019). Desafios da sociedade da informação na recuperação e uso de informações em ambientes digitais. Revista Digital Biblioteconomia e Ciência da Informação, 17, 1-16. doi: 10.20396/rdbci.vo17io.8655973

Faraco, C. A. (2011). Aspectos do pensamento estético de Bakhtin e seus pares. Letras de Hoje, 46(1), p. 21-26.

Feenberg, A. (1999) A filosofia da tecnologia numa encruzilhada. Disponível em http://www. sfu.ca/ andrewf/portu1.htm. Acesso em 17 Nov. 2020.

Fernandez, P. (2017) The technology behind fake news. Livrary hi tech news, 7, 1-5. doi: 10.1108/ LHTN-07-2017-0054

Herman, E. S., \& Chomsky, N. (2002). Manufacturing Consent: The Political Economy of the Mass Media. New York: Pantheon.

Hua, J., \& Shaw, R. (2020) Corona Virus (COVID-19) “Infodemic” and Emerging Issues through a Data Lens: The Case of China. International Journal of Environmental Research and Public Health. 17(7), 1-12. doi: 10.339o/ijerph17072309

Ioannidis, J. P. (2020) Coronavirus disease 2019: The harms of exaggerated information and non-evidence-based measures. European Journal of Clinical Investigation, 50(4), 1-5. doi: 10.1111/eci.13222

Kulak, Ö. (2020) Reconsidering the spectacle of capitalism in politics. Dialektika: Revista de Investigación Filosófica y Teoría Social, 2(5), 1-16. https://journal.dialektika.org/ojs/ index.php/logos/article/view/34

Lana, R. M. et al. (2020) Emergência do novo coronavírus (SARS-CoV-2) e o papel de uma vigilância nacional em saúde oportuna e efetiva. Caderno de Saúde Pública, 36(3), eooo19620. doi:10.1590/0102-311xooo19620

Lukács, G. (2012). Para uma ontologia do ser social. São Paulo: Boitempo.

Marés, C. \#Verificamos: É montagem tuíte de 'O Globo' dizendo que paciente com coronavírus mordeu médico. Agência Lupa, 2020a. Disponível em https://piaui.folha.uol.com. br/lupa/2020/o1/28/verificamos-globo-coronavirus/

Marx, K. (2013). O Capital: crítica da economia política, livro I: o processo de produção do capital. São Paulo: Boitempo.

Mascaro, A. L. (2020). Crise e pandemia [recurso eletrônico]. São Paulo: Boitempo.

Messeder Neto, H. S. (2019). A divulgação científica em tempos de obscurantismo e de fake news: contribuições histórico-críticas. In Rocha, M. B., \& Dalmo, R. (Org.), Divulgação científica: textos e contextos. São Paulo: Livraria da Física, p. 13-23.

Moraes, D. (2010). Comunicação, hegemonia e contra-hegemonia: a contribuição teórica de Gramsci. Revista Debates, 4(1), 54-77. doi:10.22456/1982-5269.12420

Silveira JR., A. (2014). A filosofia como historicidade: a ideologia no estudo filosófico dos Cadernos do cárcere. Serviço Social \& Sociedade, 119, 560-581. doi:10.1590/So10166282014000300008

Sociedades Secretas. Notícia Bomba. Facebook, 2020. Disponível em: https://www.facebook. com/884889578542676/posts/1083407362024229/

Schwartz, A. B. (2015). Broadcast hysteria: Orson Welle's War of the Worlds and the art of Fake News. New York: Macmillan.

Tandoc Jr., E. C., Lim, Z. W., \& Ling, R. (2018). Defining “Fake News”. Digital Journalism, 6(2), 137-153. doi:10.1080/21670811.2017.1360143

Turk, Z. (2018). Technology as Enabler of Fake News and a Potential Tool to Combat It. Docu- 
ment prepared for Policy Department for Economic, Scientific and Quality of Life Policies, European Parliament. doi:10.2861/22852

Van Duyn, E., Collier, J. (2019). Priming and fake news: the effects of Elite Discourse on Evaluations of News Media. Mass Communication and Society, 22(1), 29-48. doi:10.108 o/15205436.2018.1511807

Volóchinov, V. (2017). Marxismo e filosofia da linguagem: problemas fundamentais do método sociológico na ciência da linguagem. São Paulo: Editora 34.

Volóchinov, V. (2019) A palavra na vida e a palavra na poesia. São Paulo: Editora 34.

Williams, R. Cultura e Materialismo. São Paulo: Editora Unesp.

WHO. (2020). Coronavirus Disease (Covid-19) Dashboard. In WORLD HEALTH ORGANIZATION. Genebra. Disponível em https://covid19.who.int/. Acesso em 28/11/2020.

\section{Apêndices}

Tabela 1. Mensagens falsas sobre coronavírus verificadas pela Agência Lupa

\begin{tabular}{|c|c|c|c|c|}
\hline & Título & $\begin{array}{l}\text { Data e meio } \\
\text { de circulação }\end{array}$ & Forma da mensagem & Conteúdo da mensagem falsa \\
\hline 1 & $\begin{array}{l}\text { Patente do } \\
\text { coronavírus }\end{array}$ & $\begin{array}{l}24 / 01 / 2020 \\
\text { Facebook }\end{array}$ & $\begin{array}{l}\text { Postagem com meme, contendo } \\
\text { imagem do coronavírus, print de site } \\
\text { de patentes com destaques no texto } \\
\text { e comediante famoso, texto no topo e } \\
\text { parte de baixo da imagem que remete } \\
\text { ao choque expresso na feição do ator. } \\
\text { Legenda lateral indicando texto e link } \\
\text { da mensagem original. }\end{array}$ & $\begin{array}{l}\text { Mensagem falsa, que usa } \\
\text { patente real de uma variante } \\
\text { do coronavírus que afeta aves. }\end{array}$ \\
\hline 2 & $\begin{array}{l}\text { A verdade } \\
\text { que a china } \\
\text { esconde }\end{array}$ & $\begin{array}{l}24 / 01 / 2020 \\
\text { Facebook }\end{array}$ & $\begin{array}{l}\text { Texto curto ( } 9 \text { linhas) com destaques } \\
\text { em caixa alta e uso de ponto de } \\
\text { exclamação, indicação de tradutora, } \\
\text { data e horário da postagem e de um } \\
\text { programa de rádio sobre o tema. }\end{array}$ & $\begin{array}{l}\text { Boato falso sobre o número de } \\
\text { infectados e mortos na china. }\end{array}$ \\
\hline 3 & $\begin{array}{l}\text { Paciente com } \\
\text { coronavírus } \\
\text { mordeu } \\
\text { médico }\end{array}$ & $\begin{array}{l}28 / 01 / 2020 \\
\text { Facebook }\end{array}$ & $\begin{array}{l}\text { Imagem de postagem de Tweet com } \\
\text { logo e indicação de fonte "Jornal O } \\
\text { Globo", texto e indicação de link seguido } \\
\text { de imagem de um aglomerado de } \\
\text { pessoas orientais com máscaras, tendo } \\
\text { sua temperatura aferida na testa por um } \\
\text { agente de segurança, como forma de } \\
\text { controle de acesso. }\end{array}$ & $\begin{array}{l}\text { Notícia falsa que expressa que } \\
\text { infectado por Covi-19 mordeu } \\
\text { médico. }\end{array}$ \\
\hline 4 & $\begin{array}{l}\text { Relação entre } \\
\text { empresa } \\
\text { chinesa e jogo } \\
\text { resident evil. }\end{array}$ & $\begin{array}{l}29 / 01 / 2020 \\
\text { Facebook }\end{array}$ & $\begin{array}{l}\text { Postagem de rede social comparando } \\
\text { imagem do logotipo de uma empresa } \\
\text { chinesa afixado à esquerda e logotipo } \\
\text { de uma empresa de jogo à direita, } \\
\text { seguidas lateralmente de texto curto ( } 5 \\
\text { linhas) explicativo. }\end{array}$ & $\begin{array}{l}\text { Boato falso que vincula uma } \\
\text { empresa de biotecnologia } \\
\text { chinesa com a empresa do jogo } \\
\text { resident evil. }\end{array}$ \\
\hline
\end{tabular}




\begin{tabular}{|c|c|c|c|c|}
\hline 5 & $\begin{array}{l}\text { Chá de erva- } \\
\text { doce pode ser } \\
\text { usado como } \\
\text { tratamento } \\
\text { contra o novo } \\
\text { coronavírus }\end{array}$ & $\begin{array}{l}31 / 0^{1 / 2020} \\
\text { Facebook }\end{array}$ & $\begin{array}{l}\text { Cartaz com imagem de fundo e texto, } \\
\text { imagens de estruturas moleculares, } \\
\text { amostra de sangue, mão com luva } \\
\text { e indicação de teste positivo para } \\
\text { coronavírus. Texto inicial dividido em } \\
\text { tópicos, seguido de breve mensagem } \\
\text { explicando a indicação do chá com } \\
\text { palavras em negrito. }\end{array}$ & $\begin{array}{l}\text { Boato Falso, que veicula } \\
\text { informações sobre prevenção } \\
\text { da Covid-19, com o consumo } \\
\text { de chás e outros alimentos. }\end{array}$ \\
\hline 6 & $\begin{array}{l}\text { Coronavírus: } \\
\text { site distorce } \\
\text { entrevista } \\
\text { para sugerir } \\
\text { possibilidade } \\
\text { de criação de } \\
\text { arma biológica }\end{array}$ & $\begin{array}{l}30 / 0^{1 / 2020} \\
\text { Diário do } \\
\text { Brasil }\end{array}$ & $\begin{array}{l}\text { Reportagem tradicional composta } \\
\text { especialmente por texto e uma imagem. } \\
\text { Na imagem há cinco pessoas vestindo } \\
\text { roupa de proteção típicas de epidemias } \\
\text { em direção à entrada de um prédio } \\
\text { (possivelmente um hospital). }\end{array}$ & $\begin{array}{l}\text { Notícia Falsa que sugere a } \\
\text { criação em laboratório do novo } \\
\text { como arma biológica chinesa. } \\
\text { A notícia foi veiculada por } \\
\text { Washington times, traduzida e } \\
\text { publicada pelo Diário do Brasil. }\end{array}$ \\
\hline 7 & $\begin{array}{l}\text { Notícia } \\
\text { Bomba: } \\
\text { proteína do } \\
\text { coronavírus } \\
\text { similar a do } \\
\text { HIV }\end{array}$ & $\begin{array}{l}\text { 01/02/2020 } \\
\text { Facebook }\end{array}$ & $\begin{array}{l}\text { Postagem com imagem ampliada } \\
\text { do coronavírus, sobreposta pelo } \\
\text { texto "urgente" e mensagem lateral } \\
\text { explicando conteúdo da imagem. }\end{array}$ & $\begin{array}{l}\text { Boato falso, que sugere } \\
\text { o vínculo entre o novo } \\
\text { coronavírus e o vírus HIV, } \\
\text { induzindo inclusive a } \\
\text { interpretação de que o } \\
\text { primeiro foi produzido em } \\
\text { laboratório. }\end{array}$ \\
\hline 8 & $\begin{array}{l}\text { Alerta do } \\
\text { coronavírus } \\
\text { em } \\
\text { encomendas } \\
\text { da China } \mathbf{x}\end{array}$ & $\begin{array}{l}\text { 05/02/2020 } \\
\text { Facebook }\end{array}$ & $\begin{array}{l}\text { Postagem com duas imagens em } \\
\text { paralelo seguida de campo com } \\
\text { comentário sobre a imagem. Ȧ esquerda } \\
\text { um paciente oriental com máscara } \\
\text { é levado em maca por diversos } \\
\text { profissionais de saúde equipados contra } \\
\text { o vírus. À direita parece a imagem de um } \\
\text { pacote plástico com dados de postagem } \\
\text { para envio. }\end{array}$ & $\begin{array}{l}\text { Boato insustentável que } \\
\text { alega que a Covid-19 pode ser } \\
\text { transmitida pelo recebimento } \\
\text { de encomendas vindas da } \\
\text { china. }\end{array}$ \\
\hline 9 & $\begin{array}{l}\text { Olha aí um } \\
\text { dos motivos } \\
\text { dessa doença } \\
\text { Coronavírus }\end{array}$ & $\begin{array}{l}05 / 02 / 2020 \\
\text { Vídeo } \\
\text { viralizado } \\
\text { nas redes } \\
\text { sociais }\end{array}$ & $\begin{array}{l}\text { Vídeo cuja imagem de capa mostra } \\
3 \text { homens embaixo de um morcego } \\
\text { pendurado em ganchos em um grande } \\
\text { galpão, acompanhado das ações de } \\
\text { curtir, compartilhar e com uma breve } \\
\text { legenda. }\end{array}$ & $\begin{array}{l}\text { Vídeo falso que mostra } \\
\text { mercado que vende morcego } \\
\text { na 'China'. Na verdade o vídeo } \\
\text { foi feito na Indonésia por um } \\
\text { programa de culinária. }\end{array}$ \\
\hline 10 & $\begin{array}{l}\text { Paciente em } \\
\text { hospital no } \\
\text { Maranhão foi } \\
\text { diagnosticado } \\
\text { com novo } \\
\text { coronavírus }\end{array}$ & $\begin{array}{l}\text { 05/02/2020 } \\
\text { Luis Cardoso } \\
\text { (site) }\end{array}$ & $\begin{array}{l}\text { Estilo de texto jornalístico, com título } \\
\text { em negrito e cor diferente do texto, } \\
\text { indicação de data e categoria da } \\
\text { notícia, subtítulo em destaque e texto } \\
\text { explicativo. }\end{array}$ & $\begin{array}{l}\text { Notícia (blog) falsa que indica } \\
\text { que criança estava infectada } \\
\text { com o novo coronavírus por } \\
\text { meio da apresentação de } \\
\text { prontuário médico. }\end{array}$ \\
\hline 11 & $\begin{array}{l}\text { Imagem de } \\
\text { satélite aponta } \\
\text { possível } \\
\text { cremação } \\
\text { em massa na } \\
\text { China devido } \\
\text { ao coronavírus }\end{array}$ & $\begin{array}{l}\text { 13/02/2020 } \\
\text { Opinião } \\
\text { \& crítica - } \\
\text { revista digital }\end{array}$ & $\begin{array}{l}\text { Assume o layout de uma notícia } \\
\text { jornalística, com título em destaque, } \\
\text { subtítulo, imagem de satélite e de } \\
\text { pessoa com vestuário de proteção } \\
\text { (macacão, máscara, etc) em paralelo ao } \\
\text { texto, legenda na imagem e atribuição } \\
\text { de autoria e data para a informação. }\end{array}$ & $\begin{array}{l}\text { Notícia Falsa que alega que há } \\
\text { cremação em massa na China } \\
\text { devido ao número de mortos } \\
\text { por Covid-19. }\end{array}$ \\
\hline
\end{tabular}

1 https://piaui.folha.uol.com.br/lupa/2020/04/o8/verificamos-latam-coronavirus-vacunas/ $2 \mathrm{https} / /$ piaui.folha.uol.com.br/lupa/2020/o3/3o/verificamos-latam-china-coronavirus/ 3 https://piaui.folha.uol.com.br/lupa/2020/04/o8/verificamos-latam-tuit-coronavirus/ 
4. https://piaui.folha.uol.com.br/lupa/2020/04/o8/verificamos-latam-empresa-resident-evil-coronavirus/

5 https://piaui.folha.uol.com.br/lupa/2020/o3/30/verificamos-latam-anis-coronavirus/ 6 https://politica.estadao.com.br/blogs/estadao-verifica/coronavirus-site-distorce-entrevista-para-sugerir-

possibilidade-de-criacao-de-arma-biologica/

7 https://piaui.folha.uol.com.br/lupa/2020/04/og/verificamos-latam-hiv-coronavirus/

8 https://piaui.folha.uol.com.br/lupa/2020/04/og/verificamos-latam-encomiendas-coronavirus/

9 https://piaui.folha.uol.com.br/lupa/2020/o4/og/verificamos-latam-mercado-indonesia-coronavirus/

10 https://piaui.folha.uol.com.br/lupa/2020/04/o8/verificamos-latam-maranon-coronavirus/

11 https://piaui.folha.uol.com.br/lupa/2020/o3/3o/verificamos-latam-cremacion-coronavirus/ 
